\section{Forcetron: An Instrument to Aid in Retaining Various Components in Lingual Sheath}

\section{Abstract}

Lingual sheath is used for various purposes in orthodontics especially for the incorporation of wire components into the treatment which includes TPA, Lingual arch, Quad helix, NiTi expanders etc. These components need to be retained in place using ligatures. But to prevent the use of ligature to enhance the oral hygiene we have introduced this instrument, which helps in snuggling the wire components to the sheath and retain it in place.

Keywords: Lingual sheath; TPA; Ligation; Fixation; Quad helix

Received: October 29, 2016; Accepted: November 21, 2016; Published: November 25, 2016

\section{Introduction}

With the increasing need for oral hygiene the use of ligatures in being replaced by self retaining appliances. In the need to retain various appliances in the lingual sheath, we have designed an instrument named as FORCETRON, which uses basic mechanism of spring force to fix the wire components to the lingual sheath thereby snugly fitting the component to the appliance system.

\section{Instrument Design and Principle}

Instrument is basically a modification of Crown remover (Figures 1A-1C). The instrument consists of: 1) Head; 2) Body (Shaft); 3) Spring; 4) Force knob; 5) Stopper; and 6) A tip.

Depending on the force required, the spring is compressed using force knob and left so that the spring back will create force which is transferred to the stopper then to the tip which presses the lingual sheath and thereby creates dent in the sheath so that the component is fit in sheath and do not come out by itself (Figure 2A and 2B).

\section{Principle}

The force of spring is transferred to the lingual sheath via stopper and the tip. The force producing component is the spring. The components fir into the sheath due to dent produced and friction which holds the wire component into the sheath.

\section{Advantages \\ 1. Easy to fabricate. \\ 2. Easy to use.}

\section{Bansal $\mathrm{A}^{1}$, Tandel $\mathbf{N}^{1}$, Naik $A^{1}$ and Patel $\mathrm{S}^{1}$}

1 Department of Orthodontics, Vaidik Dental College and Research Center, Daman and Diu, India

Corresponding author: Abhishek Bansal

”ashi142002@yahoo.co.in

Apollo Towers, Khatkiwad, Nani Daman-396210, Daman and Diu, India.

Tel: 0096611-5886240

Citation: Bansal A. Forcetron: An Instrument to Aid in Retaining Various Components in Lingual Sheath. J Orthod Endod. 2016, 2:4.

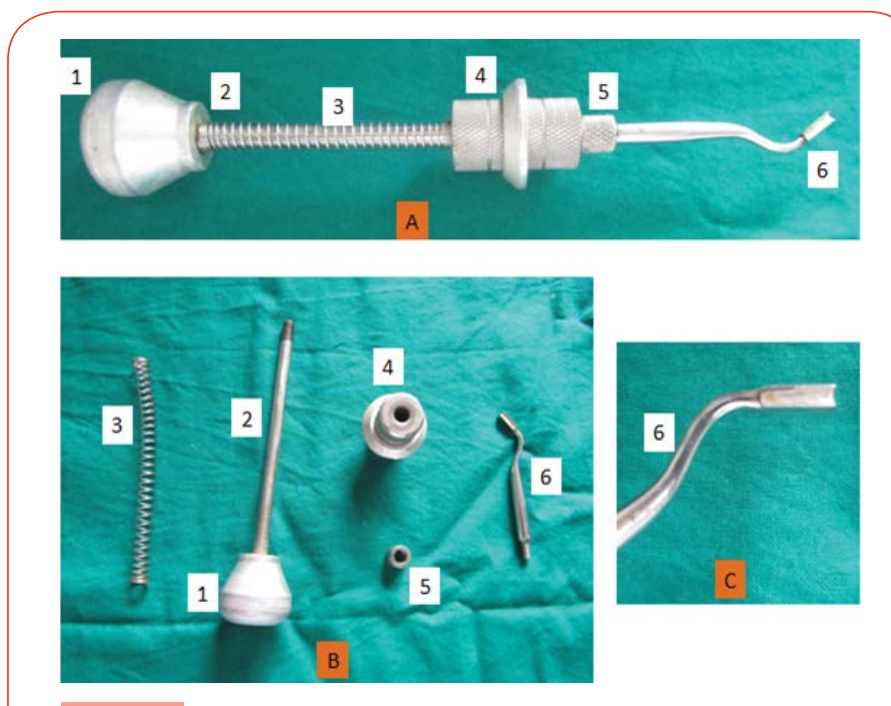

Figure 1 Instrument design.

3. No wire components are left near sheath, so helps in maintaining oral hygiene as there is no plaque retentive factor.

4. No soft tissue injury so no chances of ulceration to the tongue due to wires.

5. Cheap and can be sterilized. 


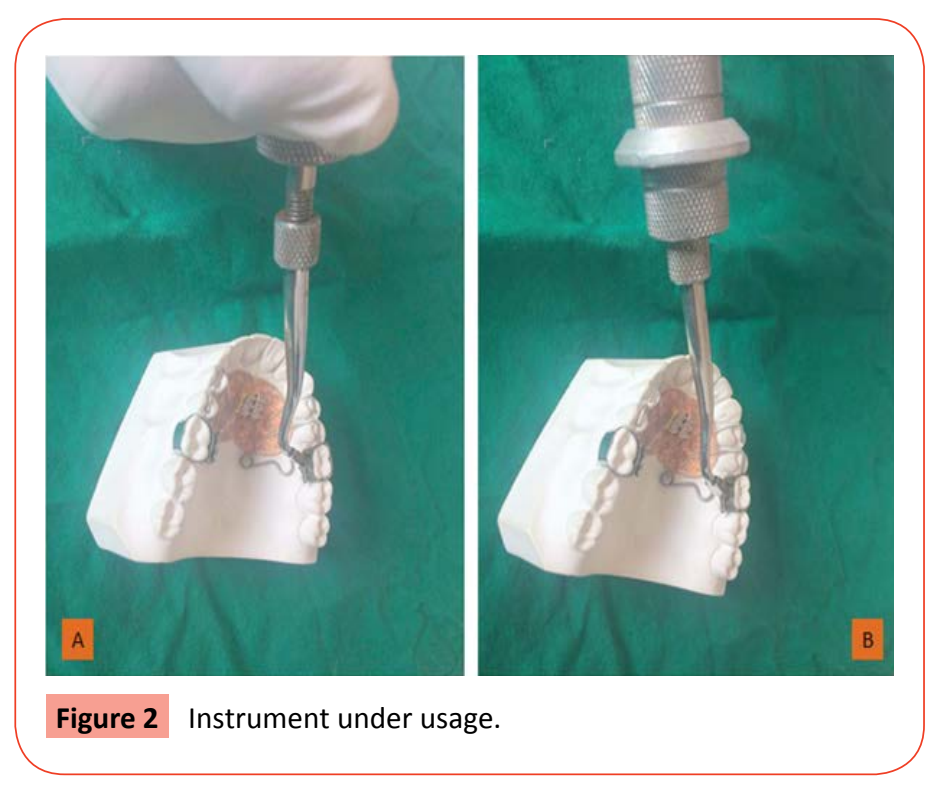

\section{Disadvantage}

1. When used in periodontically weak tooth precaution should be taken as the force is transferred to the tooth.

2. When activated, creates a momentary pain to the patient. Uses

It is used for attachment of following in the lingual sheath [1-7].

1. Trans-palatal arch.

2. Quad helix.

3. Lingual arch.

4. Ni Ti expanders.

5. Nance button.

6. Tongue cribs.

7. Modified trans-palatal arch with sleeve etc. 


\section{References}

1 Proffit WR (2000) Contemporary orthodontics (3 ${ }^{\text {rd }}$ edn.). Mosby Publications.

2 Marcotte MR (1990) Biomechanics in Orthodontics. Penn Decker. Philadelphia.

3 Burstone CJ (1989) Precision lingual arches: Active applications. J Clin Orthod 23: 101-109.
4 Burstone CJ (1994) The precision lingual arch: hinge cap attachment. J Clin Orthod 28: 151-158.

5 Burstone CJ, Manhartsberger C (1988) Precision lingual arches: Passive applications. J Clin Orthod 22: 444-451.

6 McNamara JA, Brudon W (2002) Orthodontics and dentofacial orthopedics. In: Arbor A (ed.) Needham Press p: 208.

7 Ashish G, Sridhar K, Gaurav G, Abhishek G, Ankur K, et al. (2013) A modified Transpalatal arch with sleeve. J Ind Orthod Soc 47: 112. 